\title{
Application for Introduction to Augmented Reality-Based Transportation Tools for Children
}

\section{Aplikasi Pengenalan Alat Transportasi Berbasis Augmented Reality Untuk Anak - Anak}

\author{
Ardhi Pradana ${ }^{1}$, Yulian Findawati ${ }^{2}$ \\ \{ ardhipradana544@gmail.com $^{1}$, yulianfindawati@umsida.ac.id ${ }^{2}$ \} \\ ${ }^{1,2}$ Program Studi Informatika, Sains \& Teknologi \\ Universitas Muhammadiyah Sidoarjo, Indonesia
}

\begin{abstract}
The introduction of a means of transportation to children can stimulate the brain to imagine and train creativity. With the development of information technology, means of introducing means of transportation can be done using devices such as computers, laptops or smartphones. The development of Augmented Reality technology on smartphones will make it easier for children to get to know several types of transportation that they often encounter. The purpose of writing this article is to create an application for Introduction to Transportation Tools using Augmented Reality technology for children.

The method used in making this application of Introduction to Transportation Tools is observation and interviews. The production begins with collecting data on what types of transportation will be made as a model using the Blender software. Augmented Reality application design uses Unity software by designing markers made from the Vuforia platform. The features in this application are several types of transportation that are displayed in $3 D$ with sound and information using Augmented Reality technology.

The results of testing the Transportation Tool Introduction application can run on various Android mobile devices. It has been tested on several different smartphone brands and specifications - the results of the Transportation Tool Introduction can run smoothly except under Android version 4.3 (Jellybean). Based on the test results contained in the Application of Introduction to Transportation Tools using Augmented Reality, it is suitable for introducing more interesting and innovative types of transportation to early childhood. There are still many deficiencies that can be developed, for example, increasing the number of $3 D$ objects in the transportation tool and making animations even better, so that the application is more interesting, interactive, and easy to understand.
\end{abstract}

Keywords : Introduction to Transportation Equipment, Augmented Reality, Marker, Android

\begin{abstract}
Abstrak. Pengenalan alat transportasi kepada anak dapat merangsang otak untuk berimajinasi dan melatih kreatifitas. Dengan berkembangnya teknologi informasi, sarana pengenalan alat transportasi dapat dilakukan menggunakan perangkat berupa komputer, laptop maupun smartphone. Perkembangan teknologi Augmented Reality pada smartphone akan mempermudah anak - anak dalam mengenal beberapa jenis dari alat transportasi yang sering dijumpainya. Tujuan penulisan artikel ini adalah untuk membuat aplikasi Pengenalan Alat Transportasi menggunakan teknologi Augmented Reality untuk anak - anak.

Metode yang dilakukan dalam pembuatan aplikasi Pengenalan Alat Transportasi ini adalah observasi dan wawancara. Pembuatan diawali dengan mengumpulkan data apa saja jenis transportasi yang akan dibuat sebagai model menggunakan software Blender. Perancangan aplikasi Augmented Reality menggunakan software Unity dengan merancang marker yang dibuat dari platform vuforia. Fitur yang ada dalam aplikasi ini adalah beberapa jenis alat transportasi yang ditampilkan secara $3 D$ dengan suara dan keterangan menggunakan teknologi Augmented Reality.

Hasil dari pengujian aplikasi Pengenalan Alat Transportasi dapat berjalan pada berbagai perangkat mobile Android. Telah di uji pada beberapa merk dan spesifikasi smartphone berbeda - beda hasil dari Pengenalan Alat Transportasi dapat berjalan dengan lancar kecuali dibawah android versi 4.3 (Jellybean). Berdasarkan hasil pengujian yang terdapat pada aplikasi Pengenalan Alat Transportasi menggunakan Augmented Reality ini cocok untuk memperkenalkan jenis - jenis alat transportasi kepada anak usia dini yang lebih menarik dan inovatif. Masih banyak kekurangan yang dapat dikembangkan, misalnya memperbanyak objek 3D alat transportasi tersebut dan membuat animasi yang lebih baik lagi, agar aplikasi lebih menarik, interaktif, dan mudah dipahami.
\end{abstract}

Kata kunci : Pengenalan Alat Transportasi, Augmented Reality, Marker, Android 

mengarah pada interaksi manusia dengan sebuah objek maúpün virtual. Perkembangan teknologi Augmented Reality mulai dikembangkan dalam pemahamannya akan 3 dimensi, yaitu dimana informasi dan progress seperti manusia. Menurut bahasa Augmented Reality atau AR adalah sebuah teknologi desain dengan memasukkan visual 3D ke dalam kehidupan nyata dengan menggunakan media berupa kertas, objek langsung atau perangkat masukkan tertentu sehingga bisa membuat bentuk visual objek terlihat seperti real dan nyata. Teknologi Augmented Reality (AR) mengajak para pengguna untuk saling berkomunikasi secara real-time dengan visual 3D. Augmented Reality juga bisa digunakan untuk edukasi.

Pengguna Augmented Reality (AR) ${ }^{\circ}$ pada saat ini semakin kreatif dan dapat dipastikan penggunaan pada teknologi Augmented Reality $(A R)$ akan semakin maju dan berkembang secara meluas. Teknologi Augmented Reality $(A R)$ juga pasti akan semakin berkembang maju dikarenakan Augmented Reality (AR) bisa mempermudah suatu pekerjaan. Contoh nya seperti penjualan miniatur bangunan suatu gedung dengan menunjukkan model 3D dan ditampilkan secara virtual. Contoh lainnya seperti penjualaan produk sparepart kendaraan bermotor, penjualan properti, dan lain - lain. Pekerjaan - pekerjaan tersebut bila menggunakan teknologi Augmented Reality $(A R)$ akan mampu mengurangi dan menghemat biaya pengeluaran yang besar, menghemat waktu, serta menghemat tenaga. Adapun selain dari beberapa contoh tersebut, Augmented Reality (AR) juga mampu diterapkan pada bidang arsitek, edukasi pengenalan hewan secara $3 \mathrm{D}$, dan industrial sehingga mampu membantu para pengguna untuk mevisualisasikan objek yang lebih nyata dan real. (Tedy Gorbala, Bregga dan Hariadi, Mochammad 2010).

Pembelajaran tentang perkenalan alat transportasi ini dapat lebih mudah dipahami dan dimengerti dengan media yang menarik dan menyenangkan oleh anak - anak. Maka dari itu penulis disini mencoba untuk menggabungkan teknologi Augmented Reality (AR) ini dengan edukasi pengenalan alat transportasi kepada anak - anak. Karena teknologi Augmented Reality (AR) pada saat ini sedang berkembang pesat dan menarik untuk memperkenalkan beberapa jenis alat transportasi dalam edukasi yang ditujukan kepada anak - anak usia dini terutama.

Dengan media smartphone yang berbasis android untuk menampilkan dan menunjukkan teknologi Augmented Reality (AR) akan sangat membantu bagi guru di sekolah sebagai media belajar dan orang tua di rumah untuk memperkenalkan kepada anak - anak. Oleh karena itu penulis tertarik untuk membuat sebuah aplikasi Augmented Reality (AR) tersebut, dengan membuat penulisan berjudul "Aplikasi Pengenalan Alat Transportasi Berbasis Augmented Reality Untuk Anak - Anak", dimana inputan tersebut merupakan marker yang diproses , sedangkan output nya adalah sebuah gambar 3D.

\section{METODE}

Adapun metode pengumpulan data dan informasi yang digunakan adalah sebgaai berikut : (1) Pengamatan (Observasi), Observasi dilakukan untuk mendapatkan informasi lebih detail tentang hal yang terkait dengan Augmented Reality ini dan untuk mengetahui konten yang diharapkan pengguna sebelum pembangun Augmented Reality; (2) Kuesioner, kuesioner adalah teknik pengumpulan data yang dilakukan dengan cara memberikan seperangkat pertanyaan atau pernyataan kepada orang lain yang dijadikan responden untuk dijawabnya.

\section{HASIL DAN PEMBAHASAN}

Dalam pembuatan Augmented Reality ada beberapa tahapan yang perlu dilakukan. Tahapan - tahapan yang akan dilakukan, dari mulai membuat desain merancang 3D pada Blender, Pembuatan Marker ,Import marker ke vuforia , pembuatan Augmented Reality serta alur dari Applikasi Augmented Reality ini.

\section{Desain $3 D$}

Dalam Applikasi ini desain 3D dibuat menggunakan software Blender.

Perancangan pada blender merupakan tampilan pembuatan salah satu 3D object alat transportasi dengan menggunakan software blender yang terdapat 3 tampilan pada gambar diatas, yaitu mulai pembuatan, pengeditan dan kemudian hasil rendering. Setelah model 3D object selesai dibuat, kemudian model 3D object dirender dan di export agar bisa dibaca di software unity untuk pembuatan Augmented Reality.

2. Pembuatan marker

Pembuatan marker menggunakan applikasi software developer yang bernama Vuforia 
Procedia of Engineering and Life Science Vol. 1 No.1 March 2021

Seminar Nasional \& Call Paper Fakultas Sains dan Teknologi (SENASAINS $1^{\text {st }}$ )

Universitas Muhammadiyah Sidoarjo

Gambar 2.1 Gambar Login

Setelah mendaftar dan berhasil login maka muncul tampilan seperti yang bisa di lihat di gambar 2.1
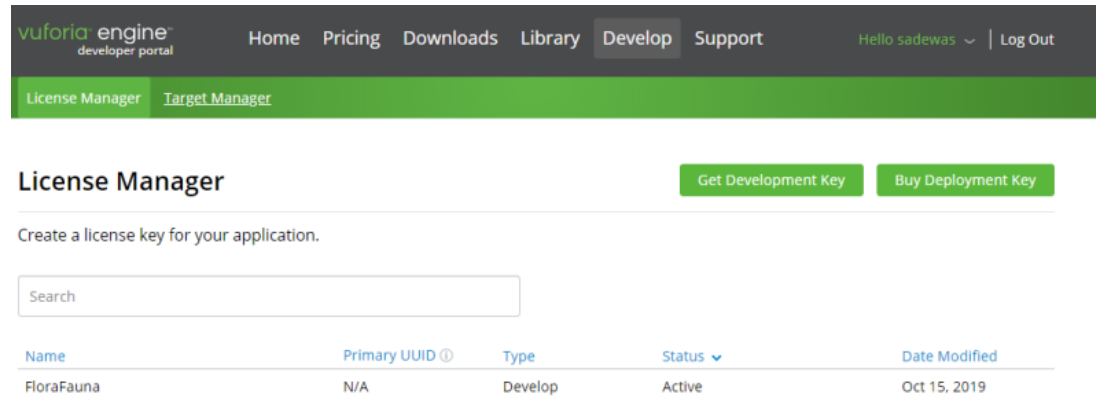

Gambar 2.2 Gambar untuk mendapatkan license manager
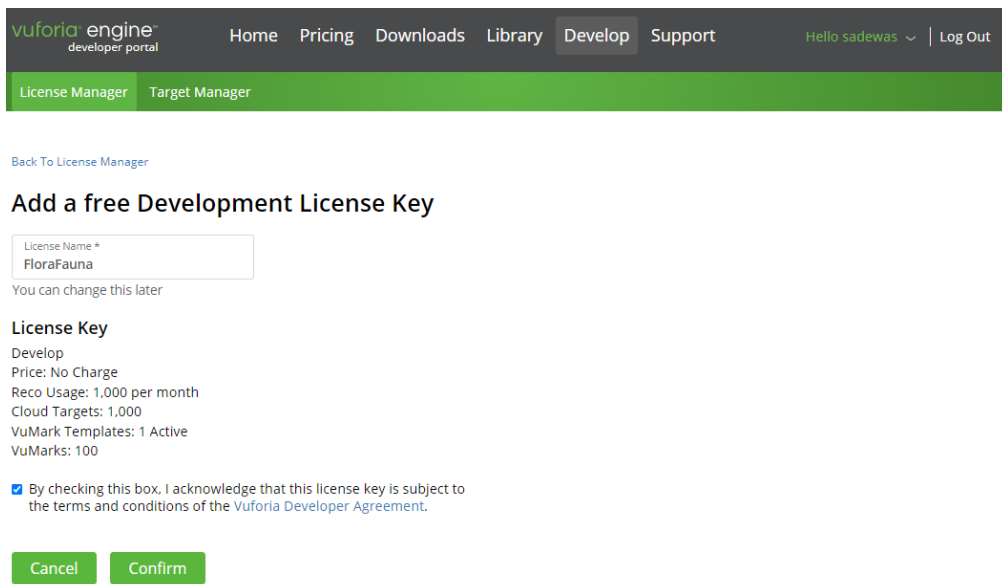

Gambar 2.3 Gambar Setelah mendapatkan license manager

3. Pembuatan Fitur

Ada dua button dalam interface awal dari Aplikasi Augmented Reality ini, ketika salah satu tombol itu ditekan maka akan keluar objek yang mewakili objek itu, berikut tombol yang ada di dalam $A R$ ini :

1. Tombol Menu

2. Tombol About

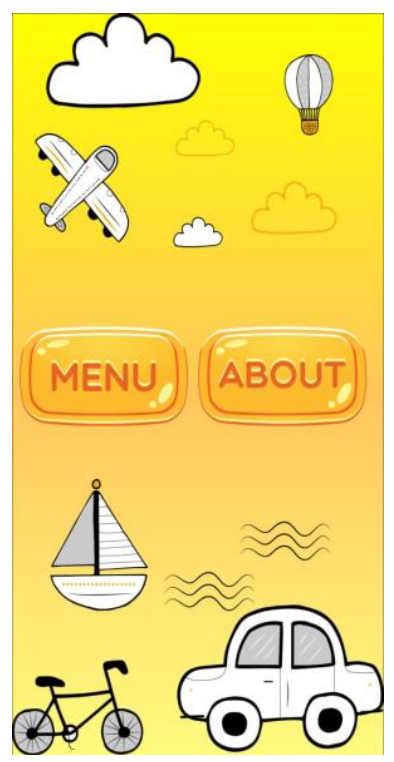

Gambar 3.1 Fitur dalam Aplikasi Augmented Reality 
Procedia of Engineering and Life Science Vol. 1 No.1 March 2021

Seminar Nasional \& Call Paper Fakultas Sains dan Teknologi (SENASAINS $1^{\text {st }}$ )

Universitas Muhammadiyah Sidoarjo

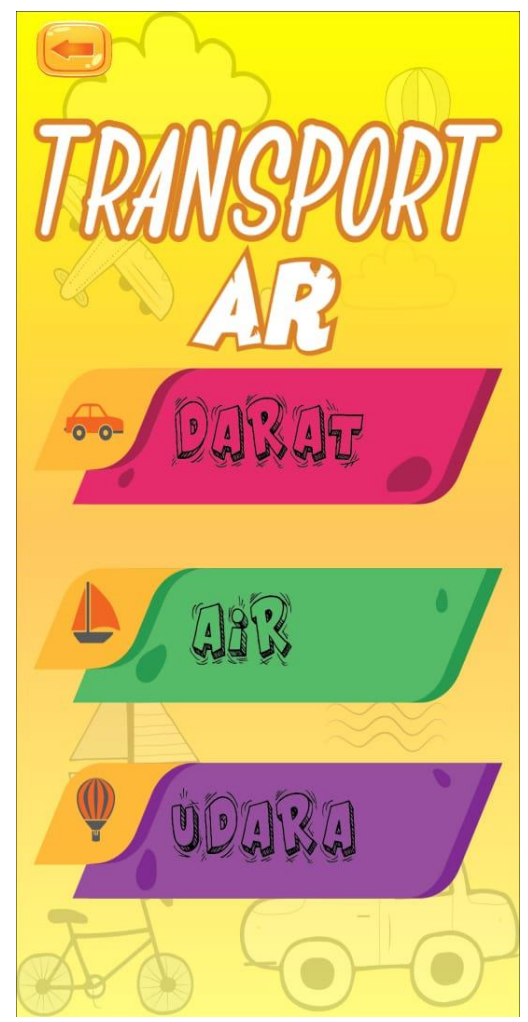

Gambar 3.2 Fitur dalam Button Menu

4. Tampilan 3D

Tampilan 3D yang keluar bisa dilihat dari 3 arah tapi tetap dalam konteks didalam tampilan layar handphone yang seakan akan seperti nyata

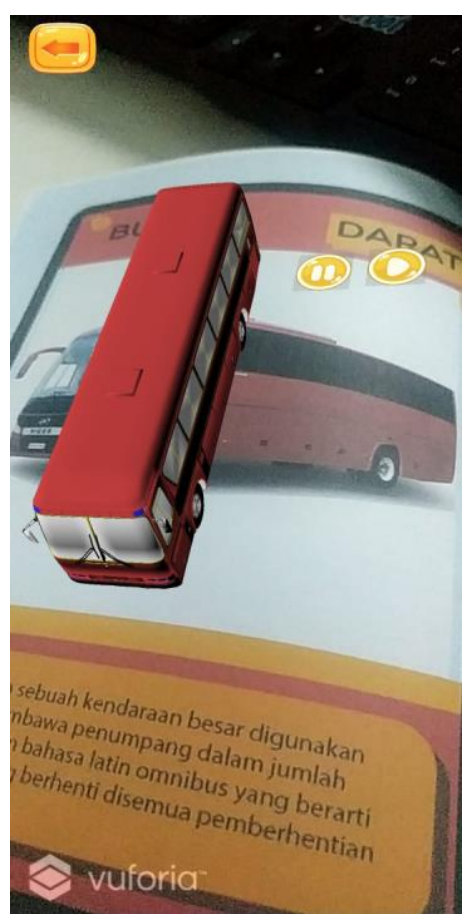

Gambar 3.3 Tampilan 3D 
Procedia of Engineering and Life Science Vol. 1 No.1 March 2021

Seminar Nasional \& Call Paper Fakultas Sains dan Teknologi (SENASAINS $1^{\text {st }}$ )

Universitas Muhammadiyah Sidoarjo

\section{Hasil perancangan :}

\section{A. Tampilan ScreenSplash}

Halaman splash (Splashscreen) adalah halaman yang pertama kali muncul dan akan menghilang secara otomatis setelah beberapa saat yang kemudian akan mengarah ke halaman menu utama.

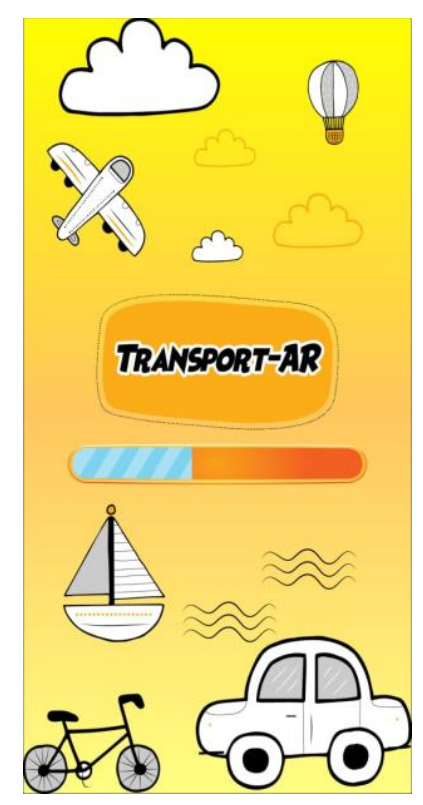

Gambar. 3.4 Tampilan screensplash 
Procedia of Engineering and Life Science Vol. 1 No.1 March 2021

Seminar Nasional \& Call Paper Fakultas Sains dan Teknologi (SENASAINS $1^{\text {st }}$ )

Universitas Muhammadiyah Sidoarjo

\section{B. Tampilan Main Menu}

Halaman tampilan main menu akan muncul secara otomatis setelah muncul tampilan screenplash.

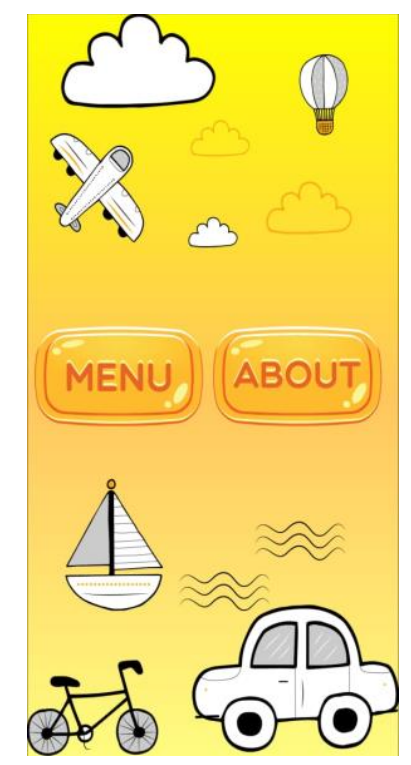

Gambar 3.5 Tampilan awal masuk menu utama

Pengguna akan masuk ke menu dan terdapat 3 tombol menu yaitu Darat, Laut, dan Udara. Tampilan main menu dapat dilihat di gambar 3.6

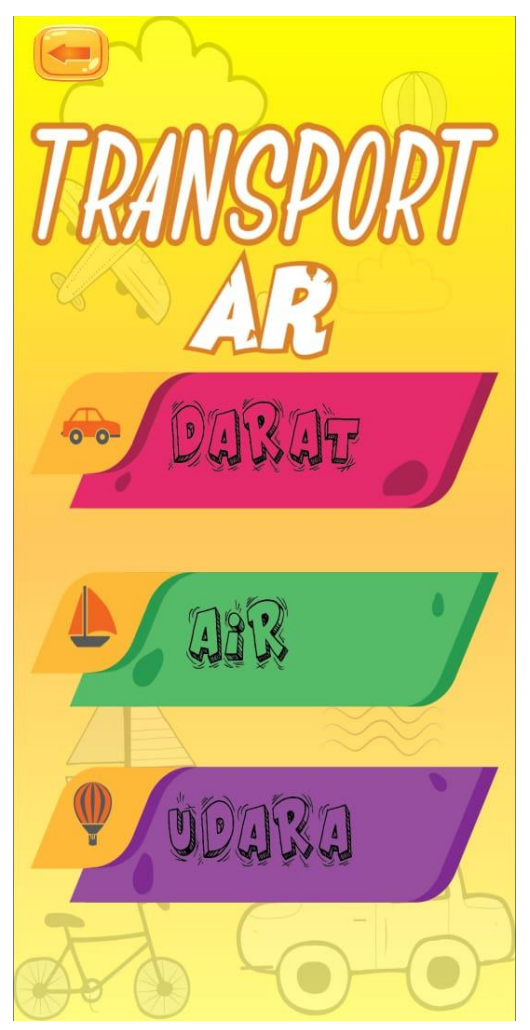

Gambar 3.6 Tampilan menu utama

\section{Tampilan Menu ABOUT}

Menu ini menampilkan informasi tentang profil dari sang pembuat aplikasi. 


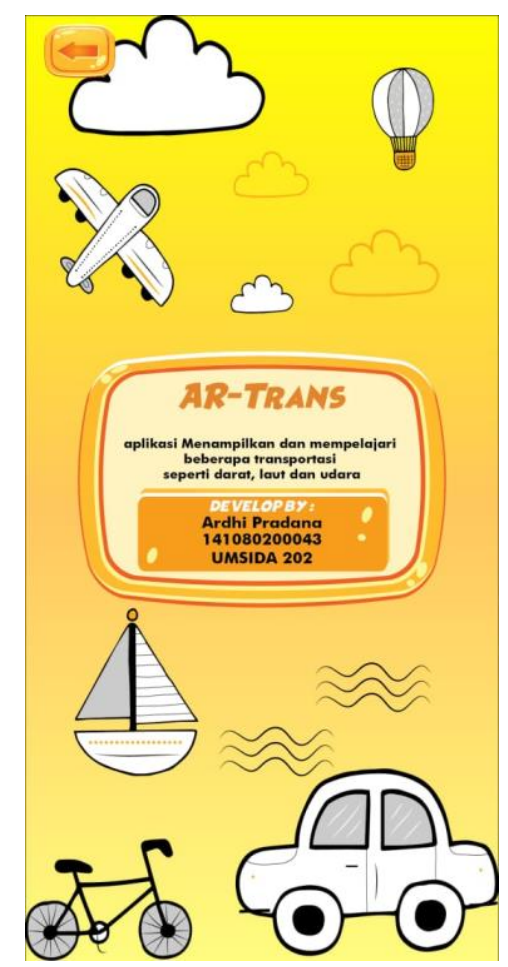

Gsmbar 3.7 Tampilan Menu TENTANG yaitu:

Pengujian dilakukan pada 15 anak - anak di TK Az-Zahra, Gemurung - Gedangan dapat diambil hasil,

1. Menurut siswa, bagaimana cara menggunakan aplikasi pengenalan alat transportasi ?

Tabel 3.1 hasil dari kuesioner

\begin{tabular}{|c|c|c|c|}
\hline \multirow{2}{*}{ Siswa } & \multicolumn{3}{|c|}{ Hasil Pertanyaan } \\
\hline & Setuju & Kurang Setuju & Tidak Setuju \\
\hline 1 & $\mathbf{v}$ & $\mathbf{x}$ & $\mathbf{x}$ \\
\hline 2 & $\mathbf{v}$ & $\mathbf{x}$ & $\mathbf{x}$ \\
\hline 3 & $\mathbf{v}$ & $\mathbf{x}$ & $\mathbf{x}$ \\
\hline 4 & $\mathbf{v}$ & $\mathbf{x}$ & $\mathbf{x}$ \\
\hline 5 & $\mathbf{v}$ & $\mathbf{x}$ & $\mathbf{x}$ \\
\hline 6 & $\mathbf{v}$ & $\mathbf{x}$ & $\mathbf{x}$ \\
\hline 7 & $\mathbf{v}$ & $\mathbf{x}$ & $\mathbf{x}$ \\
\hline 8 & $\mathbf{v}$ & $\mathbf{x}$ & $\mathbf{x}$ \\
\hline 9 & $\mathbf{v}$ & $\mathbf{x}$ & $\mathbf{x}$ \\
\hline 10 & $\mathbf{v}$ & $\mathbf{x}$ & $\mathbf{x}$ \\
\hline 11 & $\mathbf{v}$ & $\mathbf{x}$ & $\mathbf{x}$ \\
\hline 12 & $\mathbf{v}$ & $\mathbf{x}$ & $\mathbf{x}$ \\
\hline 13 & $\mathbf{X}$ & $\mathbf{v}$ & $\mathbf{x}$ \\
\hline 14 & $\mathbf{X}$ & V & $\mathbf{x}$ \\
\hline 15 & $\mathbf{x}$ & V & $\mathbf{x}$ \\
\hline Jumlah & 15 & $\mathbf{0}$ & $\mathbf{0}$ \\
\hline
\end{tabular}

Hasil : Berdasarkan dari pertanyaan di atas didapatkan jawaban yang sangat memuaskan karena terbukti bawah anak-anak yang mencoba Aplikasi ini pun sangat menikmati saat mencoba.

Hasil : Berdasarkan pertanyaan di atas oleh responden anak - anak tentang tampilan Aplikasi Pengenalan Alat Transportasi Berbasis Augmented Reality yang telah di mainkan adalah sangat bagus, terbukti dengan tingkat 
Procedia of Engineering and Life Science Vol. 1 No.1 March 2021

Seminar Nasional \& Call Paper Fakultas Sains dan Teknologi (SENASAINS $1^{\text {st }}$ )

Universitas Muhammadiyah Sidoarjo

peroleh terbanyak adalah sangat bagus. Berdasarkan hasil dari kuesioner di atas dan mengacu pada skala likert dapat diambil hasil maupun kesimpulan, yaitu 85\% anak setuju dengan Applikasi Pengenalan Alat Transportasi sebagai Media alternatif untuk menunjang belajar mengajar yang Sangat Menarik untuk digunakan.

\section{KESIMPULAN}

Anak - anak mendapatkan wawasan tentang Alat Transportasi berbentuk 3D dari sebuah aplikasi, karena dalam aplikasi ini terdapat pengetahuan yg dapat menarik minat anak untuk belajar transportasi.

Sebuah sarana media belajar mengajar yang menyenangkan untuk anak - anak dari sebuah aplikasi pengenalan alat transportasi berbasis augmented reality.

\section{UCAPAN TERIMA KASIH}

Penulis mengucapkan terima kasih kepada kedua orang tua, keluarga, teman - teman yang membantu doa dan dukungan. Jajaran Civitas Akademik Universitas Muhammadiyah Sidoarjo; Cindy Taurusta, S.ST., M.T, selaku dosen penguji ; Staff Pengajar dan Dosen Pembimbing

\section{REFERENSI}

[1] Andi, Ana. Mobile programming. Pengembangan Aplikasi Untuk Android Phone, Yogyakarta, Skripta, 2013.

[2] Bagas, D. A. S. Aplikasi Media Pembelajaran Pengenalan Profesi Untuk Anak TK Menggunakan Augmented Reality Berbasis Android. Sidoarjo, 2018, pp. 7-8.

[3] Chung, K. N. Computers in Human Behavior. 2008,pp. 88-104.

[4] Elize, F. Pengembangan Bahan Ajar Berbasis Multimedia Interaktif Mata Kuliah Gambar Listrik Yang Menggunakan Autocad Pada Program Studi Pendidikan Teknik Elektro FT UNP. Jurnal Teknik Informasi dan Pendidikan, Vol.6 No.2, 2013, pp.63-89.

[5] Fitriyah, N. Brosur Interaktif Penerimaan Mahasiswa Baru Dengan Menggunakan Augmented Reality. Universitas Muhammadiyah Sidoarjo, 2013, pp. 7-8.

[6] Gartner. Cloud Computing Will Be As Influential As E- Business, STAMFORD, Conn, 2008.

[7] Hardiansyah, F.F, S. F. Augmented Reality Untuk Mengetahui Fasilitas Umum Berbasis Android, PENS-ITS (Politeknik Elektronika Negeri Surabaya), 2008.

[8] Hernowo, T. e. Rancang Bangun Edugame Pembelajaran Kesehatan Gigi Untuk Anak - Anak Berbasis Unity 3D, 2014.

[9] Hirzer, Martin. Marker Detection For Augmented Reality Applications, 2008.

[10] Milgram, P., \& Kishino. Taxonomy Of Mixed Reality Visual Display. IEICE Transaction on Information and Systems, E77-D(12), 1994, pp. 1321-1329.

[11] Nazzarudin, S. Pemrograman Aplikasi Mobile Smartphone Dan Tablet PC Berbasis Android. Bandung : Informatika, 2012.

[12] Riana Indriani, B. S. Pembuatan Augmented Reality Tentang Pengenalan Hewan Untuk Anak Usia Dini Berbasis Android Menggunakan Metode Image Tracking Vuforia. Teknologi, 2016. 